\title{
Article \\ The Relationship between Body Composition, Dietary Intake, Physical Activity, and Pulmonary Status in Adolescents and Adults with Cystic Fibrosis
}

Kevin J. Scully 1,2 (D, Laura T. Jay ${ }^{3}$, Steven Freedman ${ }^{2,4}$, Gregory S. Sawicki ${ }^{2,5}$, Ahmet Uluer ${ }^{2,5,6}$, Joel S. Finkelstein ${ }^{2,7}$ and Melissa S. Putman $2,7, *$ (D)

Citation: Scully, K.J.; Jay, L.T.; Freedman, S.; Sawicki, G.S.; Uluer, A.; Finkelstein, J.S.; Putman, M.S. The Relationship between Body Composition, Dietary Intake, Physical Activity, and Pulmonary Status in Adolescents and Adults with Cystic Fibrosis. Nutrients 2022, 14, 310. https://doi.org/10.3390/ nu14020310

Academic Editors: Maria R. Mascarenhas and Jessica Alvarez

Received: 10 December 2021

Accepted: 10 January 2022

Published: 12 January 2022

Publisher's Note: MDPI stays neutral with regard to jurisdictional claims in published maps and institutional affiliations.

Copyright: (C) 2022 by the authors. Licensee MDPI, Basel, Switzerland. This article is an open access article distributed under the terms and conditions of the Creative Commons Attribution (CC BY) license (https:// creativecommons.org/licenses/by/ $4.0 /)$.
1 Division of Endocrinology, Boston Children's Hospital, Boston, MA 02115, USA; kevin.scully@childrens.harvard.edu

2 Harvard Medical School, Boston, MA 02115, USA; sfreedma@bidmc.harvard.edu (S.F.); gregory.sawicki@childrens.harvard.edu (G.S.S.); Ahmet.Uluer@childrens.harvard.edu (A.U.); finkelstein.joel@mgh.harvard.edu (J.S.F.)

3 Division of Gastroenterology, Hepatology and Nutrition, Boston Children's Hospital, Boston, MA 02115, USA; laura.jay@childrens.harvard.edu

4 Division of Gastroenterology, Beth Israel Deaconess Hospital, Boston, MA 02115, USA

5 Division of Pulmonary Medicine, Boston Children's Hospital, Boston, MA 02115, USA

6 Division of Pulmonary and Critical Care Medicine, Brigham and Women's Hospital, Boston, MA 02115, USA

7 Division of Endocrinology, Massachusetts General Hospital, Boston, MA 02115, USA

* Correspondence: msputman@partners.org; Tel.: +1-857-218-5017; Fax: +1-617-730-0194

\begin{abstract}
Measures of body fat and lean mass may better predict important clinical outcomes in patients with cystic fibrosis (CF) than body mass index (BMI). Little is known about how diet quality and exercise may impact body composition in these patients. Dual X-ray absorptiometry (DXA) body composition, 24-h dietary recall, and physical activity were assessed in a cross-sectional analysis of 38 adolescents and adults with CF and 19 age-, race-, and gender-matched healthy volunteers. Compared with the healthy volunteers, participants with CF had a lower appendicular lean mass index (ALMI), despite no observed difference in BMI, and their diets consisted of higher glycemic index foods with a greater proportion of calories from fat and a lower proportion of calories from protein. In participants with CF, pulmonary function positively correlated with measures of lean mass, particularly ALMI, and negatively correlated with multiple measures of body fat after controlling for age, gender, and BMI. Higher physical activity levels were associated with greater ALMI and lower body fat. In conclusion, body composition measures, particularly ALMI, may better predict key clinical outcomes in individuals with CF than BMI. Future longitudinal studies analyzing the effect of dietary intake and exercise on body composition and CF-specific clinical outcomes are needed.
\end{abstract}

Keywords: body composition; cystic fibrosis; dual-energy X-ray absorptiometry; lean body mass; appendicular lean mass index; fat mass index; dietary intake

\section{Introduction}

Nutritional optimization has long been a focus of care in patients with cystic fibrosis (CF), with body mass index (BMI) being utilized as the primary marker of health and survival [1-3]. Undernutrition in CF has been associated with worsening pulmonary status, decreased exercise tolerance, immunologic impairment, impaired growth, decreased quality of life, and a shorter life expectancy [4-6]. Conversely, optimized nutritional status is associated with improved lung function, clinical outcomes and survival $[7,8]$. As a result of this, nutritional guidelines recommend maintaining a body mass index (BMI) at or above the 50 th percentile of age for children and adolescents, and a level of at least $22 \mathrm{~kg} / \mathrm{m}^{2}$ in adult females and $23 \mathrm{~kg} / \mathrm{m}^{2}$ in adult males aged 18 and over. In the past, this concern for malnutrition has often led to physicians recommending high-calorie diets without concern 
for diet quality [9]. This has led to a tendency for individuals with CF to overconsume energy-dense, nutrient-poor foods, particularly foods high in added sugars and refined carbohydrates that have a high glycemic index [9-12].

Life expectancy and clinical outcomes for patients with CF have significantly improved with widespread use of highly effective cystic fibrosis transmembrane conductance regulator (CFTR) modulators, including the risk for undernutrition [6]. However, advancements in CF care have also led to significantly increased rates of overweight and obesity [13-17]. Additionally, the prevalence of non-pulmonary complications such as CFrelated diabetes (CFRD) continues to increase, particularly as the CF population ages [18,19]. At present, there are few published studies investigating the impact of these high-calorie, lower-quality diets on body composition and the development of CF-related metabolic comorbidities $[9,20]$.

While BMI has classically been the primary measure of nutritional outcomes in patients with $\mathrm{CF}$, there is interest in evaluating other potentially more meaningful predictors of health status $[9,20]$. There is growing evidence that BMI may not accurately reflect body composition, particularly the distinction between fat mass and fat-free mass [21-23]. As a result, the use of BMI as the primary marker of nutritional status in CF may have significant drawbacks in routine clinical care.

Dual-energy X-ray absorptiometry (DXA) body composition analysis has become increasingly utilized in individuals with $\mathrm{CF}$, particularly given its ability to provide more detailed information regarding the distribution of fat mass, lean mass, and bone density [20]. Several groups have described an increased prevalence of normal weight obesity (NWO) and decreased fat-free mass distribution (FFMD) in individuals with CF, as well as a link between this type of body habitus and poorer lung function $[20,24,25]$. There may exist specific DXA body composition variables that better predict long-term CF-specific clinical outcomes than BMI [26]. If identified, these variables could predict the risk of pulmonary decline and metabolic abnormalities in patients with $\mathrm{CF}$, and help guide individualized advice regarding dietary composition and physical activity.

We performed a cross-sectional analysis comparing the dietary intake, physical activity, and DXA body composition measures in adolescents and adults with CF and age-, race- and gender-matched healthy volunteers. We also investigated how body composition correlated with pulmonary status and dietary intake in participants with CF. We hypothesized that adults with CF would have higher carbohydrate intake, greater fat mass, and lower lean mass than healthy volunteers, and that measures of lean mass would correlate more strongly with percent predicted forced expiratory volume in 1 second (FEV1) than BMI.

\section{Materials and Methods}

\subsection{Participants and Eligibility Criteria}

Cross-sectional data were analyzed from the baseline visit of a prospective observational study investigating the effect of ivacaftor on bone density and microarchitecture in individuals with CF [27]. Participants with CF were recruited from the Massachusetts General Hospital and Boston Children's Hospital Cystic Fibrosis Center. Exclusion criteria for participants with $\mathrm{CF}$ included history of solid organ transplantation, current pregnancy, and Burkholderia dolosa infection (due to institutional infection control issues). Matched healthy volunteers were recruited from the community. Exclusion criteria for healthy volunteers included current pregnancy, a history of medications or disorders known to affect bone metabolism, cumulative use of oral glucocorticoids for greater than two months, or $\mathrm{BMI}<18.5$ or $>30 \mathrm{~kg} / \mathrm{m}^{2}$ (or $<5$ th percentile or $>95$ th percentile for pediatric participants) at the time of screening.

The parent study included children and adults with CF and at least one copy of the G551D mutation, who were matched by age ( \pm 2 years and by Tanner stage in pediatric participants), race, and gender to a cohort of participants with CF and other CFTR mutations, and to a cohort of healthy volunteers. For the present analysis, only post-pubertal (Tanner stage V) participants aged 15 years and above were included, due to the rapid and 
variable changes in diet and body composition occurring during growth. The protocol was approved by the Mass General Brigham Institutional Review Board (IRB) with ceded review by the Boston Children's Hospital IRB and was registered on clinicaltrials.gov (NCT01549314). Written informed consent was obtained from all participants.

\subsection{Clinical Assessments}

All participants were queried regarding medical history, medication use including oral and inhaled glucocorticoids, alcohol and tobacco use, and pubertal and reproductive history. Tanner staging in pediatric participants was performed by a board-certified pediatric endocrinologist. Additional data obtained from participants with CF included the number of CF exacerbations in the past year, defined as treatment with intravenous antibiotics and/or hospitalization. CFTR genotype and percent predicted forced expiratory volume in $1 \mathrm{~s}$ (FEV1) in the most recent pulmonary function testing were obtained in participants with $\mathrm{CF}$ by chart review. In all participants, height was measured on a wall-mounted stadiometer and weight on an electronic scale. Race and ethnicity were self-reported. Serum glucose and insulin levels were obtained after fasting at least $8 \mathrm{~h}$ overnight; these data were used to calculate a homeostatic model assessment for insulin resistance (HOMA-IR), with a level $>2$ considered consistent with insulin resistance [28].

\subsection{Dietary Intake and Physical Activity Assessments}

A registered dietician assessed nutritional intake with a 24-h dietary recall. Dietary composition of fat $(\mathrm{g})$, protein $(\mathrm{g})$, and carbohydrates $(\mathrm{g})$, percentage of calories from each macronutrient, total energy (kcal), added sugar (g), glycemic index (GI) and glycemic load as defined by the International Carbohydrate Quality Consortium (ICQC) [29], were quantified using the validated Nutrient Data System for Research (NDSR) [30]. Physical activity was also assessed by a registered dietician using the Modifiable Activity Questionnaire, a self-reported tool that assesses each individual's degree of physical activity over the last 1 year, based on 40 leisure and occupational activity items, ranging in intensity [31].

\subsection{Assessment of Body Composition}

Whole and regional body composition analyses were obtained from whole body DXA scans (Discovery A, Hologic Inc., Bedford, MA, USA). To account for variants in stature, height-normalized indexes were determined for fat-mass and lean mass (mass in $\mathrm{kg}$ /height in $\mathrm{m}^{2}$ ). DXA quality control included daily measurement of a Hologic DXA anthropomorphic spine phantom and visual review of all images by an experienced investigator.

Participants were classified as normal weight (BMI 18-24.9 kg/m²), overweight (BMI $25-29.9 \mathrm{~kg} / \mathrm{m}^{2}$ ), or obese (BMI $\geq 30 \mathrm{~kg} / \mathrm{m}^{2}$ ). Normal weight obesity (NWO) was defined as those with a normal BMI $<25 \mathrm{~kg} / \mathrm{m}^{2}$ but with a body fat percentage of $>30 \%$ in women and $>23 \%$ in men $[20,32]$.

\subsection{Statistical Analyses}

Statistical analyses were performed using STATA (version 16, StataCorp LLC, College Station, TX, USA). Normality was assessed for all variables using the Shapiro-Wilk test. Clinical characteristics, dietary intake, and body composition measures were compared between participants with CF and healthy volunteers using independent $t$-tests or Wilcoxon rank sum tests for normally and non-normally distributed data, respectively. Categorical variables were compared using chi square tests. In participants with $C F$, the relationship between body composition measures and FEV1 or dietary intake variables was determined via Pearson or Spearman correlation analysis, for normally and non-normally distributed data, respectively. Multivariable regression analysis was used to assess the relationship between various body composition measures and FEV1 Two regression models were used to adjust for potential confounding effects: Model 1, adjusting for age and gender; Model 
2, adjusting for age, gender and BMI. A $p$-value of $<0.05$ was considered statistically significant.

\section{Results}

\subsection{Clinical Characteristics}

Thirty-eight adolescents and adults with $\mathrm{CF}$ and 19 healthy volunteers were included in the analysis. Clinical characteristics are summarized in Table 1. Participants ranged in age from 15 to 56 years and included eight adolescents with CF and four adolescent healthy volunteers aged $15-17$ years. There were no significant differences between age, gender, race/ethnicity, anthropometric measures, HOMA-IR, or physical activity between the participants with $\mathrm{CF}$ and the healthy volunteers. Of the participants with $\mathrm{CF}, 30(78.9 \%)$ had a history of pancreatic insufficiency and $5(13.2 \%)$ had a history of CFRD. Five of the participants with $\mathrm{CF}$ without CFRD had fasting glucose levels consistent with impaired fasting glucose (100-125 mg/dL). Approximately half of these individuals $(n=20,52.6 \%)$ were heterozygous and seven (18.4\%) were homozygous for the F508del mutation. As the initial CF cohort was recruited to study the effects of ivacaftor on BMD, half $(n=19)$ of these participants had the G551D mutation. Ten participants (26.3\%), all of whom had the G551D mutation, were taking ivacaftor, which was initiated within three months of the study visit. No other modulators were available for clinical use at the time of study enrollment. In the 12 months prior to the study visit, thirteen (34\%) of the participants with CF experienced one or more $\mathrm{CF}$ exacerbations and $15(40 \%)$ reported treatment with systemic glucocorticoids. Three of the participants with CF were overweight (BMI $\geq 25 \mathrm{~kg} / \mathrm{m}^{2}$ ), and two were obese $\left(\mathrm{BMI} \geq 30 \mathrm{~kg} / \mathrm{m}^{2}\right)$. Of the remaining 32 participants, approximately one-third $(n=10,31.25 \%)$ met criteria for NWO, including five women $(33.3 \%)$ and five men $(29.4 \%)$.

\subsection{Body Composition and Dietary Intake in Participants with CF and Healthy Volunteers}

Comparisons of DXA body composition measures between participants with $\mathrm{CF}$ and healthy volunteers are presented in Table 2. Participants with CF had a lower appendicular lean mass $/$ height $^{2}$ (appendicular lean mass index, ALMI) compared with the healthy volunteers. All other body composition measures were similar between the two cohorts. As shown in Table 2, participants with CF reported a significantly higher total fat intake, greater \% calories from fat, higher glycemic index, and lower \% calories from protein than the healthy volunteers.

\subsection{Relationship between Body Composition and Pulmonary Function in Participants with CF}

Table 3 presents the results of correlation analyses and multiple linear regression models for FEV1 and DXA body composition measures in the participants with CF $(n=38)$. On univariable correlation analysis, only ALMI was significantly correlated with FEV1. When controlling for age and gender (regression Model 1), FEV1 showed significant positive correlations with lean mass, lean mass $/$ height $^{2}$ (lean mass index, LMI), and ALMI. Subsequent analysis adjusting for age, gender, and BMI (regression Model 2) displayed an even stronger relationship between FEV1 and ALMI (Figure 1), but the relationship with LMI was no longer significant. In addition, a significant negative correlation between FEV1 and fat measures ( $\%$ fat, trunk $\%$ fat, and fat mass $/$ height $^{2}$ (fat mass index, FMI)) was noted when age, gender, and BMI were included in the model. BMI was significantly correlated with FEV1; however, this significance was lost after adjusting for age and gender. 
Table 1. Clinical Characteristics.

\begin{tabular}{|c|c|c|c|}
\hline & CF $(n=38)$ & Healthy Volunteers $(n=19)$ & $p$-Value \\
\hline Age (years) & $27.9 \pm 2.0$ & $28.8 \pm 2.7$ & 0.796 \\
\hline Female, $n(\%)$ & $20(52.6 \%)$ & $10(52.6 \%)$ & \\
\hline $\begin{array}{l}\text { Race, } n(\%) \\
\text { White } \\
\text { Black } \\
\text { Asian } \\
\text { Native Haqaiian or Pacific Islander } \\
\text { American Indian or Alaskan Native }\end{array}$ & $38(100 \%)$ & $19(100 \%)$ & \\
\hline $\begin{array}{l}\text { Ethnicity, } n(\%) \\
\text { Hispanic } \\
\text { Non-Hispanic }\end{array}$ & $\begin{array}{c}0(0 \%) \\
38(100 \%)\end{array}$ & $\begin{array}{c}0(0 \%) \\
38(100 \%)\end{array}$ & \\
\hline Height $(\mathrm{cm})$ & $166.9 \pm 1.5$ & $170.3 \pm 1.9$ & 0.185 \\
\hline Weight $(\mathrm{kg})$ & $59.6 \pm 1.9$ & $64.4 \pm 2.6$ & 0.154 \\
\hline BMI $\left(\mathrm{kg} / \mathrm{m}^{2}\right)$ & $21.4 \pm 0.6$ & $22.1 \pm 0.5$ & 0.447 \\
\hline HOMA-IR & $1.2 \pm 0.1$ & $1.0 \pm 0.1$ & 0.455 \\
\hline Physical Activity Score & $22.3 \pm 2.8$ & $16.4 \pm 2.6$ & 0.311 \\
\hline $\begin{array}{l}\text { Genotype, } n(\%) \\
\text { F508del homozygous } \\
\text { F508del heterozygous } \\
\text { Other }\end{array}$ & $\begin{array}{l}7(18.4 \%) \\
20(52.6 \%) \\
11(28.9 \%)\end{array}$ & & \\
\hline Pancreatic insufficiency, $n(\%)$ & $30(78.9 \%)$ & & \\
\hline FEV1 (\% predicted) & $73 \pm 5$ & & \\
\hline CFRD, $n(\%)$ & $5(13.2 \%)$ & & \\
\hline CF Exacerbations in the past prior year $(\mathrm{Y} / \mathrm{N})$ & $25(65.8 \%)$ & & \\
\hline Number of CF Exacerbations in the prior year & $1.5 \pm 0.25$ & & \\
\hline Glucocorticoid Use in the prior year & $15(39.5 \%)$ & & \\
\hline Ivacaftor Use, $n(\%)$ & $10(26.3 \%)$ & & \\
\hline
\end{tabular}

Data displayed as mean \pm standard error (SE) or $n(\%)$ unless otherwise indicated. BMI, body mass index $\mathrm{kg} / \mathrm{m}^{2}$, FEV1, forced expiratory volume; CFRD, cystic fibrosis related diabetes; HOMA-IR, homeostatic model assessment for insulin resistance.

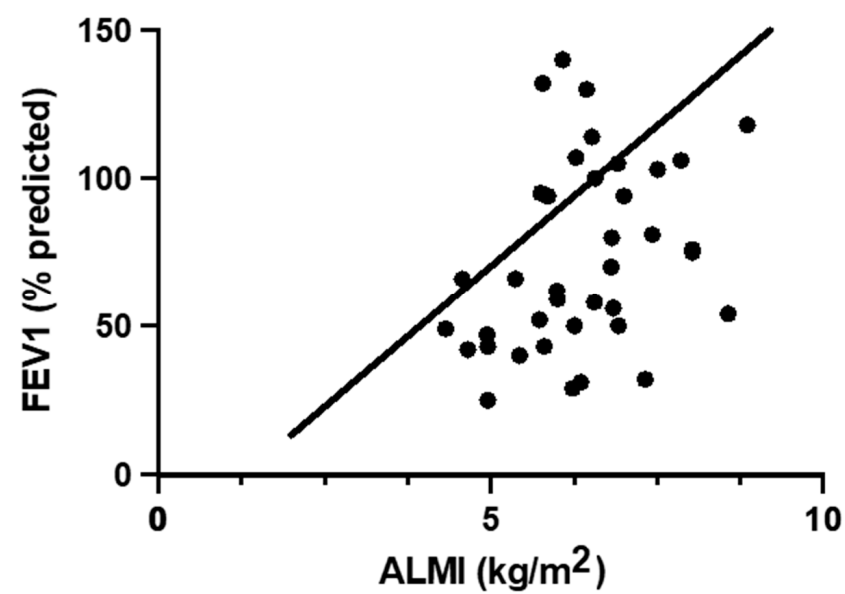

Figure 1. Multivariable regression of FEV1 vs. ALMI in participants with CF. Figure 1 displays the relationship between individuals' FEV1 and ALMI values (circles) as well as the regression line of best fit across the whole dataset when controlling for age, gender and BMI (Model 2). FEV1, \% predicted forced expiratory volume in $1 \mathrm{~s}$; ALMI, appendicular lean mass index. 
Table 2. Body composition and dietary intake in participants with CF and healthy volunteers.

\begin{tabular}{lccc}
\hline & CF $(\boldsymbol{n}=\mathbf{3 8})$ & $\begin{array}{c}\text { Healthy } \\
\text { Volunteers }(\boldsymbol{n}=\mathbf{1 9})\end{array}$ & $\boldsymbol{p}$-Value \\
\hline Body Composition & & & \\
Fat mass $(\mathrm{g})$ & $15,740 \pm 1119$ & $16,687 \pm 898$ & 0.097 \\
Lean mass $(\mathrm{g})$ & $42,438 \pm 1301$ & $46,109 \pm 2593$ & 0.352 \\
Total mass $(\mathrm{g})$ & $60,274 \pm 1940$ & $65,163 \pm 2611$ & 0.07 \\
\% fat & $25.6 \pm 1.2$ & $26.2 \pm 1.7$ & 0.778 \\
Trunk fat mass $(\mathrm{g})$ & $7051 \pm 646$ & $6709 \pm 426$ & 0.294 \\
Trunk total mass $(\mathrm{g})$ & $30,267 \pm 1111$ & $30,330 \pm 1299$ & 0.618 \\
Trunk \% fat & $22.3 \pm 1.3$ & $22.4 \pm 1.3$ & 0.52 \\
Fat mass/height ${ }^{2}\left(\mathrm{~kg} / \mathrm{m}^{2}\right)$ & $5.8 \pm 0.4$ & $5.9 \pm 0.4$ & 0.275 \\
Lean/height ${ }^{2}\left(\mathrm{~kg} / \mathrm{m}^{2}\right)$ & $15.9 \pm 0.4$ & $16.4 \pm 0.6$ & 0.481 \\
Appen lean/height ${ }^{2}\left(\mathrm{~kg} / \mathrm{m}^{2}\right)$ & $6.4 \pm 0.2$ & $7.2 \pm 0.4$ & 0.029 \\
Dietary intake & & & \\
Energy $(\mathrm{kcal})$ & $2880 \pm 258$ & $2203 \pm 196$ & 0.137 \\
Total Fat $(\mathrm{g})$ & $118.8 \pm 11.7$ & $74.8 \pm 8$ & 0.016 \\
Total Carb $(\mathrm{g})$ & $362.6 \pm 34.4$ & $292 \pm 22.3$ & 0.418 \\
Total Protein $(\mathrm{g})$ & $104 \pm 10.2$ & $96.5 \pm 11.4$ & 0.667 \\
Cholesterol $(\mathrm{mg})$ & $313.9 \pm 42.9$ & $248.3 \pm 26.9$ & 0.569 \\
\% Calories from Fat & $36.5 \pm 1.6$ & $29.3 \pm 1.3$ & 0.002 \\
\% Calories from Carbohydrates & $48.5 \pm 1.8$ & $52.8 \pm 1.4$ & 0.092 \\
\% Calories from Protein & $14.9 \pm 0.8$ & $17.2 \pm 0.8$ & 0.015 \\
Added Sugar $(\mathrm{g})$ & $120.6 \pm 17.5$ & $66.7 \pm 6.2$ & 0.142 \\
Glycemic Index & $61.4 \pm 1.2$ & $57.7 \pm 1.1$ & 0.036 \\
Glycemic Load & $213.1 \pm 22$ & $154.1 \pm 11.6$ & 0.131 \\
\hline Data & & & \\
\hline
\end{tabular}

Data displayed as mean $\pm \mathrm{SE} ; \mathrm{CF}$, cystic fibrosis.

Table 3. Correlation analyses and multiple linear regression of FEV1 vs. body composition measures in participants with CF.

\begin{tabular}{|c|c|c|c|c|c|c|}
\hline & \multicolumn{6}{|c|}{$\%$ Predicted FEV1 } \\
\hline & $\mathbf{r}$ & $p$-Value & $\begin{array}{c}\text { Model 1 } \\
\text { Beta Coefficient }\end{array}$ & $p$-Value & $\begin{array}{c}\text { Model } 2 \\
\text { Beta Coefficient }\end{array}$ & $p$-Value \\
\hline Fat mass (g) & 0.174 & 0.296 & $0.0004 \pm 0.0009$ & 0.656 & $-0.003 \pm 0.002$ & 0.051 \\
\hline Lean mass (g) & 0.194 & 0.243 & $0.003 \pm 0.001$ & 0.001 & $0.003 \pm 0.001$ & 0.003 \\
\hline$\%$ fat & 0.065 & 0.7 & $-1.12 \pm 0.992$ & 0.263 & $-4.066 \pm 0.1 .121$ & 0.001 \\
\hline Trunk fat mass (g) & 0.157 & 0.348 & $0.001 \pm 0.002$ & 0.513 & $-0.005 \pm 0.003$ & 0.111 \\
\hline Trunk total mass (g) & 0.265 & 0.108 & $0.002 \pm 0.001$ & 0.072 & $0.001 \pm 0.002$ & 0.451 \\
\hline Trunk \% fat & 0.081 & 0.629 & $-0.259 \pm 0.87$ & 0.768 & $-3.206 \pm 1.184$ & 0.011 \\
\hline FMI $\left(\mathrm{kg} / \mathrm{m}^{2}\right)$ & 0.171 & 0.305 & $-0.141 \pm 2.35$ & 0.953 & $-14.684 \pm 3.931$ & 0.001 \\
\hline LMI $\left(\mathrm{kg} / \mathrm{m}^{2}\right)$ & 0.264 & 0.11 & $5.242 \pm 2.325$ & 0.031 & $4.839 \pm 3.459$ & 0.171 \\
\hline $\operatorname{ALMI}\left(\mathrm{kg} / \mathrm{m}^{2}\right)$ & 0.332 & 0.042 & $15.021 \pm 4.45$ & 0.002 & $18.972 \pm 6.542$ & 0.007 \\
\hline BMI $\left(\mathrm{kg} / \mathrm{m}^{2}\right)$ & 0.405 & 0.012 & $2.574 \pm 1.505$ & 0.096 & & \\
\hline
\end{tabular}

Data displayed as correlation coefficient/Spearman's rho for correlation analyses or Beta coefficient \pm SE for regression models. Model 1: adjusted for age and gender; model 2: adjusted for age, gender and BMI. Significant results $(p<0.05)$ are in bold. FEV1, \% predicted forced expiratory volume in $1 \mathrm{~s}$; ALMI, appendicular lean mass index; LMI, lean mass index; FMI, fat mass index.

\subsection{Relationship of Body Composition with Dietary Intake and Physical Activity in Participants with $C F$}

Table 4 outlines the results of the correlation analysis between DXA body composition measures, dietary intake components, and physical activity scores. Multiple measures of body fat composition, particularly fat mass, \% fat, and FMI, negatively correlated with total amount of macronutrients (energy, fat, carbohydrate and protein), though the relative proportion of each macronutrient intake did not correlate with body composition. Added sugar and glycemic load both negatively correlated with multiple measures of body fat, including \% fat and FMI. Lean mass, LMI, and ALMI were not significantly associated 
with dietary composition. HOMA-IR did not significantly correlate with any DXA body composition measures or dietary variables (data not shown).

Table 4. Correlation analyses between dietary intake and body composition in participants with CF.

\begin{tabular}{|c|c|c|c|c|c|c|c|c|c|c|c|}
\hline & $\begin{array}{c}\text { Energy } \\
\text { (kcal) }\end{array}$ & $\begin{array}{l}\text { Total Fat } \\
\text { (g) }\end{array}$ & $\begin{array}{c}\text { Total } \\
\text { Carb (g) }\end{array}$ & $\begin{array}{l}\text { Total } \\
\text { Protein } \\
\text { (g) }\end{array}$ & $\%$ Cal Fat & $\begin{array}{l}\% \text { Cal } \\
\text { Carb }\end{array}$ & $\begin{array}{c}\% \text { Cal } \\
\text { Protein }\end{array}$ & $\begin{array}{l}\text { Added } \\
\text { Sugars } \\
\text { (g) }\end{array}$ & $\begin{array}{c}\text { GI } \\
\text { (Glucose) }\end{array}$ & $\begin{array}{c}\mathrm{GL} \\
\text { (Glucose) }\end{array}$ & $\begin{array}{l}\text { Physical } \\
\text { Activity }\end{array}$ \\
\hline $\begin{array}{l}\text { Fat mass } \\
(\mathrm{g})\end{array}$ & $\begin{array}{l}-0.533 \\
(0.002)\end{array}$ & $\begin{array}{l}-0.498 \\
(0.004)\end{array}$ & $\begin{array}{l}-0.445 \\
(0.012)\end{array}$ & $\begin{array}{l}-0.508 \\
(0.004)\end{array}$ & $\begin{array}{c}0.091 \\
(0.626)\end{array}$ & $\begin{array}{l}-0.104 \\
(0.576)\end{array}$ & $\begin{array}{c}0.096 \\
(0.608)\end{array}$ & $\begin{array}{l}-0.354 \\
(0.051)\end{array}$ & $\begin{array}{l}-0.036 \\
(0.846)\end{array}$ & $\begin{array}{l}-0.445 \\
(0.012)\end{array}$ & $\begin{array}{l}-0.469 \\
(0.003)\end{array}$ \\
\hline $\begin{array}{l}\text { Lean } \\
\text { mass (g) }\end{array}$ & $\begin{array}{c}0.181 \\
(0.331)\end{array}$ & $\begin{array}{c}0.194 \\
(0.296)\end{array}$ & $\begin{array}{c}0.073 \\
(0.696)\end{array}$ & $\begin{array}{c}0.277 \\
(0.131)\end{array}$ & $\begin{array}{c}0.248 \\
(0.179)\end{array}$ & $\begin{array}{l}-0.26 \\
(0.158)\end{array}$ & $\begin{array}{c}0.161 \\
(0.389)\end{array}$ & $\begin{array}{c}0.005 \\
(0.979)\end{array}$ & $\begin{array}{c}-0.024 \\
(0.9)\end{array}$ & $\begin{array}{l}0.072 \\
(0.70)\end{array}$ & $\begin{array}{c}0.304 \\
(0.068)\end{array}$ \\
\hline$\%$ fat & $\begin{array}{c}-0.679 \\
(<0.0001)\end{array}$ & $\begin{array}{l}-0.621 \\
(0.0002)\end{array}$ & $\begin{array}{l}-0.512 \\
(0.003)\end{array}$ & $\begin{array}{c}-0.705 \\
(<0.0001)\end{array}$ & $\begin{array}{l}-0.041 \\
(0.827)\end{array}$ & $\begin{array}{c}0.084 \\
(0.653)\end{array}$ & $\begin{array}{c}0.015 \\
(0.936)\end{array}$ & $\begin{array}{l}-0.409 \\
(0.022)\end{array}$ & $\begin{array}{l}-0.024 \\
(0.898)\end{array}$ & $\begin{array}{l}-0.481 \\
(0.006)\end{array}$ & $\begin{array}{c}-0.55 \\
(0.0004)\end{array}$ \\
\hline $\begin{array}{l}\text { Trunk fat } \\
\text { mass (g) }\end{array}$ & $\begin{array}{l}-0.54 \\
(0.002)\end{array}$ & $\begin{array}{l}-0.504 \\
(0.004)\end{array}$ & $\begin{array}{l}-0.443 \\
(0.013)\end{array}$ & $\begin{array}{l}-0.536 \\
(0.002)\end{array}$ & $\begin{array}{c}0.084 \\
(0.655)\end{array}$ & $\begin{array}{l}-0.08 \\
(0.668)\end{array}$ & $\begin{array}{c}0.017 \\
(0.928)\end{array}$ & $\begin{array}{l}-0.334 \\
(0.066)\end{array}$ & $\begin{array}{l}-0.057 \\
(0.763)\end{array}$ & $\begin{array}{l}-0.451 \\
(0.011)\end{array}$ & $\begin{array}{l}-0.457 \\
(0.005)\end{array}$ \\
\hline $\begin{array}{l}\text { Trunk \% } \\
\text { fat }\end{array}$ & $\begin{array}{c}-0.65 \\
(0.0001) \\
\end{array}$ & $\begin{array}{r}-0.618 \\
(0.0002) \\
\end{array}$ & $\begin{array}{l}-0.512 \\
(0.003)\end{array}$ & $\begin{array}{c}-0.684 \\
(<0.0001)\end{array}$ & $\begin{array}{c}0.016 \\
(0.931)\end{array}$ & $\begin{array}{l}-0.009 \\
(0.962)\end{array}$ & $\begin{array}{l}-0.02 \\
(0.916)\end{array}$ & $\begin{array}{l}-0.349 \\
(0.054)\end{array}$ & $\begin{array}{l}-0.035 \\
(0.853)\end{array}$ & $\begin{array}{l}-0.508 \\
(0.004)\end{array}$ & $\begin{array}{c}-0.532 \\
(0.0007)\end{array}$ \\
\hline $\begin{array}{l}\text { FMI } \\
\left(\mathrm{kg} / \mathrm{m}^{2}\right)\end{array}$ & $\begin{array}{l}-0.626 \\
(0.0002)\end{array}$ & $\begin{array}{r}-0.567 \\
(0.0009)\end{array}$ & $\begin{array}{l}-0.525 \\
(0.002)\end{array}$ & $\begin{array}{r}-0.623 \\
(0.0002)\end{array}$ & $\begin{array}{c}0.097 \\
(0.605)\end{array}$ & $\begin{array}{l}-0.097 \\
(0.604)\end{array}$ & $\begin{array}{c}0.049 \\
(0.794)\end{array}$ & $\begin{array}{l}-0.409 \\
(0.022)\end{array}$ & $\begin{array}{l}-0.051 \\
(0.784)\end{array}$ & $\begin{array}{l}-0.517 \\
(0.003)\end{array}$ & $\begin{array}{l}-0.51 \\
(0.001)\end{array}$ \\
\hline $\begin{array}{l}\mathrm{LMI} \\
\left(\mathrm{kg} / \mathrm{m}^{2}\right)\end{array}$ & $\begin{array}{l}-0.135 \\
(0.469)\end{array}$ & $\begin{array}{l}-0.099 \\
(0.595)\end{array}$ & $\begin{array}{l}-0.223 \\
(0.228)\end{array}$ & $\begin{array}{c}0.012 \\
(0.949)\end{array}$ & $\begin{array}{c}0.192 \\
(0.301)\end{array}$ & $\begin{array}{c}-0.271 \\
(0.14)\end{array}$ & $\begin{array}{c}0.259 \\
(0.159)\end{array}$ & $\begin{array}{l}-0.196 \\
(0.292)\end{array}$ & $\begin{array}{l}-0.156 \\
(0.403)\end{array}$ & $\begin{array}{l}-0.228 \\
(0.219)\end{array}$ & $\begin{array}{c}0.225 \\
(0.181)\end{array}$ \\
\hline $\begin{array}{l}\text { ALMI } \\
\left(\mathrm{kg} / \mathrm{m}^{2}\right)\end{array}$ & $\begin{array}{c}0.004 \\
(0.984)\end{array}$ & $\begin{array}{c}0.063 \\
(0.737)\end{array}$ & $\begin{array}{l}-0.029 \\
(0.878)\end{array}$ & $\begin{array}{l}0.153 \\
(0.41)\end{array}$ & $\begin{array}{c}0.206 \\
(0.266)\end{array}$ & $\begin{array}{l}-0.288 \\
(0.116)\end{array}$ & $\begin{array}{c}0.232 \\
(0.209)\end{array}$ & $\begin{array}{l}-0.062 \\
(0.742)\end{array}$ & $\begin{array}{l}-0.113 \\
(0.546)\end{array}$ & $\begin{array}{l}-0.043 \\
(0.819)\end{array}$ & $\begin{array}{c}0.367 \\
(0.025)\end{array}$ \\
\hline
\end{tabular}

Data displayed as correlation coefficient/Spearman's rho $\left(p\right.$-value). Significant results $(p<0.05)$ are in bold. $\mathrm{CF}_{\gamma}$ cystic fibrosis, ALMI, appendicular lean mass index; LMI, lean mass index; FMI, fat mass index.

Physical activity score was negatively correlated with multiple measures of body fat, including fat mass, \% fat, trunk fat mass, trunk \% fat, and FMI. In contrast, ALMI was positively correlated with physical activity, with no other relationship noted between physical activity and other lean mass measures.

\section{Discussion}

In this cross-sectional study, individuals with CF had significantly lower ALMI compared with the healthy volunteers, despite no observed differences in BMI. In participants with CF, pulmonary function was positively associated with measures of lean mass but negatively associated with measures of fat mass when accounting for age, gender, and BMI, with ALMI having the strongest correlation. Higher physical activity levels were also correlated with greater ALMI and lower body fat measures. Participants with CF consumed significantly more fat, had higher glycemic index diets, and had a lower proportion of calories from protein than their healthy peers. Interestingly, measures of lean mass were not associated with key dietary intake variables in participants with CF; however, those with the lowest body fat had the greatest caloric intake, without a significant relationship to the relative macronutrient composition of their diet.

BMI has been the primary measure of nutritional status in patients with CF for many years, due to its established strong correlation with pulmonary function and mortality [1,3,6]. However, BMI does not distinguish between fat mass and lean mass, and may be an insensitive marker of both fat-free mass deficits and excess adiposity in patients with CF $[20,23,24]$. For example, in a cross-sectional study of 86 adults with CF, fat-free mass depletion was found in $14 \%$ of participants, but was undetected by BMI in $58 \%$ of cases [23]. A study by Alvarez et al., of 32 adults with CF reported that $31 \%$ had NWO, defined as $\%$ fat $>30 \%$ in women and $>23 \%$ in men in the setting of a normal BMI, and that these subjects had a lower fat free mass index and pulmonary function than overweight subjects, suggesting that excess adiposity may impact clinical outcomes even in the setting of a normal BMI [20]. In our study, we found a similar proportion of participants with NWO (31\%). In addition, we found no difference in BMI between participants with CF and healthy volunteers; however, those with CF had a significantly lower ALMI, which has been identified as an important marker of sarcopenia and low muscle mass [33]. Lower 
ALMI has been associated with increased mortality in the healthy older population [33], but this measure has not previously been reported in CF.

ALMI was also significantly correlated with pulmonary function in participants with $\mathrm{CF}$ in our study, with an even stronger relationship after adjusting for age, gender, and BMI. In contrast, BMI was correlated with FEV1 in the univariate analysis, but lost significance after adjustment for age and gender, suggesting that ALMI may be a superior measure than BMI in predicting lung function. After multivariable adjustment, lean mass was also positively associated with FEV1, whereas measures of body fat (fat mass, \% fat, and FMI) were negatively correlated with FEV1. Similar to our findings, other studies in the CF population have reported associations of lower fat-free mass or lean body mass with lower pulmonary function $[20,21,24]$. Although ALMI correlations with clinical outcomes have not previously been reported in CF, appendicular lean mass (ALM) was found to be associated with FEV1 in one study of 69 adolescents with CF [5], and another study reported a greater number of $\mathrm{CF}$ exacerbations in those with lower appendicular fat-free mass [34]. In addition, our findings of a negative correlation between body fat measures and pulmonary function are consistent with the previously cited study by Alvarez et al., in which FMI was negatively associated with FEV1 after adjusting for age, gender and BMI [20]. Altogether, these results build a strong case supporting the importance of lean mass, particularly ALMI, in promoting lung function while implicating excess adiposity in pulmonary decline.

To achieve and maintain an adequate BMI, patients with $\mathrm{CF}$ are encouraged to consume a caloric intake of $120-150 \%$ of the dietary reference intake (DRI) for the typical healthy adult [1,35-38]. The CF Foundation, American Diabetes Association (ADA), and European Society for Clinical Nutrition and Metabolism (ESPEN) recommend a similar caloric composition for children and adults with CF, comprised of $20 \%$ of calories from protein, $35-50 \%$ from fat, and $40-50 \%$ from carbohydrate, though these recommendations are built on a general consensus rather than evidence-based data $[1,36]$. Current guidelines do not specify the composition of carbohydrate intake apart from avoiding artificial sweeteners and closely monitoring carbohydrate intake to maintain glycemic control [8,36-38].

Nutritional interventions in patients with CF often target increasing or maintaining BMI with high-calorie, high-carbohydrate and high-fat diets. However, in contrast with the trends observed in the general population, the impact of such diets on body composition in adults with CF is less clear $[10,20]$. In our study, we found that participants with CF consumed a higher calorie diet driven predominately by the intake of fat, and higher glycemic foods with a lower proportion of calories from protein, as compared with healthy volunteers. Similar to our findings, a cross-sectional study of 80 children with CF aged 2-18 years (mean age 9.3 years), with age- and gender-matched controls, found that children with CF consumed significantly more energy-dense, nutrient-poor foods than the controls. In addition, another study noted significantly higher added sugar intake, lower Healthy Eating Index scores, and higher visceral adipose tissue (VAT) in 24 adults with CF compared with the matched controls [9]. Interestingly, VAT was associated with higher added sugar intake and fasting glucose levels in that study. In contrast, we found a negative correlation between body fat measures and both added sugar and glycemic load, and a negative correlation was also noted with total energy intake as well as the absolute value of all macronutrients, irrespective of macronutrient intake as a proportion of total calories. No correlations were noted between diet and any measures of lean mass. Although unexpected, these results suggest that the relative macronutrient composition of the diet may not directly impact body composition, and that those patients with the lowest body fat were consuming the greatest number of calories from all sources, perhaps related to increased metabolic needs.

Not surprisingly, physical activity levels were positively correlated with ALMI and negatively correlated with multiple measures of body fat, supporting the beneficial role of exercise on body composition and muscle health. Several prior studies have shown a strong correlation between fat-free mass (FFM) content and exercise capacity [39-41]. In 
a prospective pilot observational study of 28 adults with CF participating in an 8-week exercise training (ET) program, with 15 CF controls with no ET, Prevotat et al., found that ET resulted in an increased FFM compared with the controls [39]. Another study in 18 adolescents with CF reported that FFM measured by bioimpedance correlated with FVC $\mathrm{z}$-score, maximal inspiratory pressure, and exercise tolerance. Interestingly, BMI did not significantly correlate with pulmonary or respiratory muscle function in this study.

Strengths of this study included the comprehensive clinical, DXA, and dietary measures prospectively collected in a relatively large number of patients with $\mathrm{CF}$, as well as the inclusion of an age-, race-, and gender-matched healthy control group. However, important limitations of this study should be noted. The cross-sectional study design limited the conclusions on causality that could be drawn, and further prospective longitudinal studies investigating body composition in CF are needed. Participants were recruited from a single study center, potentially limiting the heterogeneity of the study population. Nutrition data were limited to a single 24-h diet recall, as opposed to 3-day food diary; repeated prospective data collection within participants may have provided more accurate dietary information. Similarly, physical activity was measured by survey and not by a wearable activity tracker or fitness monitor. Although there were multiple definitions of NWO in the literature, we utilized a definition that has previously been studied in CF. Given that the primary outcome for the parent study was to assess the effect of ivacaftor therapy on bone density and microarchitecture, half of the participants had the G551D mutation. A genotypically more diverse CF population may have impacted our outcomes. In addition, the small number of adolescent participants limited our ability to investigate differences between adolescents and adults. Lastly, few of the participants were on CFTR modulators at the time of the study, which could limit the applicability of these results to patients on highly effective CFTR modulator therapy.

\section{Conclusions}

In conclusion, body composition measures may more accurately predict key clinical outcomes in individuals with CF than BMI. In particular, ALMI was significantly lower in individuals with CF than healthy volunteers, despite no differences in BMI, which may have important clinical implications given the observed correlation between ALMI and pulmonary function. In contrast, FMI and other measures of body fat were negatively correlated with FEV1 when accounting for age, gender, and BMI, suggesting a detrimental effect of adiposity in CF. Our data also support the beneficial impact of physical activity on body composition, including increased ALMI and decreased body fat measures. Future prospective longitudinal studies analyzing the effect of body composition, dietary intake, and physical activity on CF-specific clinical outcomes are greatly needed, particularly in the post-modulator era.

Author Contributions: Conceptualization, K.J.S., L.T.J., S.F., G.S.S., A.U., J.S.F. and M.S.P.; data curation, M.S.P.; formal analysis, K.J.S. and M.S.P.; funding acquisition, M.S.P.; investigation, K.J.S. and J.S.F.; supervision, M.S.P.; writing—original draft, K.J.S.; writing—review and editing, L.T.J., S.F., G.S.S., A.U., J.S.F. and M.S.P. All authors have read and agreed to the published version of the manuscript.

Funding: This study was supported by NIH K23DK102600 and a Vertex Pharmaceuticals Investigator Initiated Studies Grant. Resources utilized for this study were provided by the Massachusetts General Hospital Clinical Research Center funded by the Harvard Catalyst 1UL1 TR001102.

Institutional Review Board Statement: The study approved by the Institutional Review Board of Mass General Brigham (IRB 2012P000269) with ceded review by the Boston Children's Hospital IRB and was registered on clinicaltrials.gov (NCT01549314).

Informed Consent Statement: All participants provided written informed consent. 
Data Availability Statement: Some or all datasets generated during and/or analyzed during the current study are not publicly available but are available from the corresponding author on reasonable request.

Acknowledgments: The authors would like to gratefully acknowledge the support of the dedicated staff of the MGH Clinical Research Center and the MGH and BCH Cystic Fibrosis Centers. We thank the study volunteers for their participation.

Conflicts of Interest: Putman reports grants and speaking fees from Vertex Pharmaceuticals as well as grants from the Cystic Fibrosis Foundation, outside the submitted work. Sawicki reports personal fees from Vertex Pharmaceuticals, outside the submitted work. Uluer reports grants from the Cystic Fibrosis Foundation and serves an advisory board for Vertex Pharmaceuticals and as an unpaid board member for the Cystic Fibrosis Research Institute. Freedman reports grants from the Cystic Fibrosis Foundation. The other authors have nothing to disclose.

\section{References}

1. Moran, A.; Brunzell, C.; Cohen, R.C.; Katz, M.; Marshall, B.C.; Onady, G.; Robinson, K.A.; Sabadosa, K.A.; Stecenko, A.; Slovis, B.; et al. Clinical care guidelines for cystic fibrosis-related diabetes: A position statement of the American Diabetes Association and a clinical practice guideline of the Cystic Fibrosis Foundation, endorsed by the Pediatric Endocrine Society. Diabetes Care 2010, 33, 2697-2708. [CrossRef]

2. Yen, E.H.; Quinton, H.; Borowitz, D. Better nutritional status in early childhood is associated with improved clinical outcomes and survival in patients with cystic fibrosis. J. Pediatr. 2013, 162, 530-535.e1. [CrossRef]

3. Borowitz, D.; Baker, R.D.; Stallings, V. Consensus report on nutrition for pediatric patients with cystic fibrosis. J. Pediatr. Gastroenterol. Nutr. 2002, 35, 246-259. [CrossRef] [PubMed]

4. Morton, A.M. Symposium 6: Young people, artificial nutrition and transitional care the nutritional challenges of the young adult with cystic fibrosis: Transition. Proc. Nutr. Soc. 2009, 68, 430-440. [CrossRef]

5. Calella, P.; Valerio, G.; Thomas, M.; McCabe, H.; Taylor, J.; Brodlie, M.; Siervo, M. Association between body composition and pulmonary function in children and young people with cystic fibrosis. Nutrition 2018, 48, 73-76. [CrossRef] [PubMed]

6. McDonald, C.M.; Alvarez, J.A.; Bailey, J.; Bowser, E.K.; Farnham, K.; Mangus, M.; Padula, L.; Porco, K.; Rozga, M. Academy of Nutrition and Dietetics: 2020 Cystic Fibrosis Evidence Analysis Center Evidence-Based Nutrition Practice Guideline. J. Acad. Nutr. Diet. 2021, 121, 1591-1636.e3. [CrossRef] [PubMed]

7. Culhane, S.; George, C.; Pearo, B.; Spoede, E. Malnutrition in cystic fibrosis: A review. Nutr. Clin. Pract. 2013, 28, 676-683. [CrossRef] [PubMed]

8. Engelen, M.P.K.J.; Com, G.; Deutz, N.E.P. Protein is an important but undervalued macronutrient in the nutritional care of patients with cystic fibrosis. Curr. Opin. Clin. Nutr. Metab. Care 2014, 17, 515-520. [CrossRef] [PubMed]

9. Bellissimo, M.P.; Zhang, I.; Ivie, E.A.; Tran, P.H.; Tangpricha, V.; Hunt, W.R.; Stecenko, A.A.; Ziegler, T.R.; Alvarez, J.A. Visceral adipose tissue is associated with poor diet quality and higher fasting glucose in adults with cystic fibrosis. J. Cyst. Fibros. 2019, 18, 430-435. [CrossRef]

10. Sutherland, R.; Katz, T.; Liu, V.; Quintano, J.; Brunner, R.; Tong, C.W.; Collins, C.E.; Ooi, C.Y. Dietary intake of energy-dense, nutrient-poor and nutrient-dense food sources in children with cystic fibrosis. J. Cyst. Fibros. 2018, 17, 804-810. [CrossRef]

11. Calvo-Lerma, J.; Boon, M.; Hulst, J.; Colombo, C.; Asseiceira, I.; Garriga, M.; Masip, E.; Claes, I.; Bulfamante, A.; Janssens, H.M.; et al. Change in Nutrient and Dietary Intake in European Children with Cystic Fibrosis after a 6-Month Intervention with a Self-Management mHealth Tool. Nutrients 2021, 13, 1801. [CrossRef] [PubMed]

12. Woestenenk, J.W.; Castelijns, S.J.A.M.; van der Ent, C.K.; Houwen, R.H.J. Dietary intake in children and adolescents with cystic fibrosis. Clin. Nutr. 2014, 33, 528-532. [CrossRef] [PubMed]

13. Panagopoulou, P.; Fotoulaki, M.; Nikolaou, A.; Nousia-Arvanitakis, S. Prevalence of malnutrition and obesity among cystic fibrosis patients. Pediatr. Int. 2014, 56, 89-94. [CrossRef] [PubMed]

14. Hanna, R.M.; Weiner, D.J. Overweight and obesity in patients with cystic fibrosis: A center-based analysis. Pediatr. Pulmonol. 2015, 50, 35-41. [CrossRef] [PubMed]

15. Stephenson, A.L.; Mannik, L.A.; Walsh, S.; Brotherwood, M.; Robert, R.; Darling, P.B.; Nisenbaum, R.; Moerman, J.; Stanojevic, S. Longitudinal trends in nutritional status and the relation between lung function and BMI in cystic fibrosis: A population-based cohort study. Am. J. Clin. Nutr. 2013, 97, 872-877. [CrossRef]

16. Harindhanavudhi, T.; Wang, Q.; Dunitz, J.; Moran, A.; Moheet, A. Prevalence and factors associated with overweight and obesity in adults with cystic fibrosis: A single-center analysis. J. Cyst. Fibros. 2020, 19, 139-145. [CrossRef]

17. Guimbellot, J.S.; Baines, A.; Paynter, A.; Heltshe, S.L.; VanDalfsen, J.; Jain, M.; Rowe, S.M.; Sagel, S.D. Long term clinical effectiveness of ivacaftor in people with the G551D CFTR mutation. J. Cyst. Fibros. 2021, 20, 213-219. [CrossRef]

18. Cystic Fibrosis Foundation. 2019 Patient Registry Annual Data Report; Cystic Fibrosis Foundation: Bethesda, MD, USA, 2019.

19. Moran, A.; Pekow, P.; Grover, P.; Zorn, M.; Slovis, B.; Pilewski, J.; Tullis, E.; Liou, T.G.; Allen, H. Cystic Fibrosis Related Diabetes Therapy Study Group. Insulin therapy to improve BMI in cystic fibrosis-related diabetes without fasting hyperglycemia: Results of the cystic fibrosis related diabetes therapy trial. Diabetes Care 2009, 32, 1783-1788. [CrossRef] 
20. Alvarez, J.A.; Ziegler, T.R.; Millson, E.C.; Stecenko, A.A. Body composition and lung function in cystic fibrosis and their association with adiposity and normal-weight obesity. Nutrition 2016, 32, 447-452. [CrossRef]

21. Ritchie, H.; Nahikian-Nelms, M.; Roberts, K.; Gemma, S.; Shaikhkhalil, A. The prevalence of aberrations in body composition in pediatric cystic fibrosis patients and relationships with pulmonary function, bone mineral density, and hospitalizations. J. Cyst. Fibros. 2021, 20, 837-842. [CrossRef]

22. Nevill, A.M.; Stewart, A.D.; Olds, T.; Holder, R. Relationship between adiposity and body size reveals limitations of BMI. Am. J. Phys. Anthropol. 2006, 129, 151-156. [CrossRef]

23. King, S.J.; Nyulasi, I.B.; Strauss, B.J.G.; Kotsimbos, T.; Bailey, M.; Wilson, J.W. Fat-free mass depletion in cystic fibrosis: Associated with lung disease severity but poorly detected by body mass index. Nutrition 2010, 26, 753-759. [CrossRef]

24. Sheikh, S.; Zemel, B.S.; Stallings, V.A.; Rubenstein, R.C.; Kelly, A. Body composition and pulmonary function in cystic fibrosis. Front. Pediatr. 2014, 2, 33. [CrossRef]

25. Baker, J.F.; Putman, M.S.; Herlyn, K.; Tillotson, A.P.; Finkelstein, J.S.; Merkel, P.A. Body composition, lung function, and prevalent and progressive bone deficits among adults with cystic fibrosis. Jt. Bone Spine 2016, 83, 207-211. [CrossRef]

26. King, S.J.; Tierney, A.C.; Edgeworth, D.; Keating, D.; Williams, E.; Kotsimbos, T.; Button, B.M.; Wilson, J.W. Body composition and weight changes after ivacaftor treatment in adults with cystic fibrosis carrying the G551 D cystic fibrosis transmembrane conductance regulator mutation: A double-blind, placebo-controlled, randomized, crossover study with open-label extension. Nutrition 2021, 85, 111124.

27. Putman, M.S.; Greenblatt, L.B.; Bruce, M.; Joseph, T.; Lee, H.; Sawicki, G.; Uluer, A.; Sicilian, L.; Neuringer, I.; Gordon, C.M.; et al. The Effects of Ivacaftor on Bone Density and Microarchitecture in Children and Adults with Cystic Fibrosis. J. Clin. Endocrinol. Metab. 2021, 106, E1248-E1261. [CrossRef]

28. Matthews, D.R.; Hosker, J.P.; Rudenski, A.S.; Naylor, B.A.; Treacher, D.F.; Turner, R.C. Homeostasis model assessment: Insulin resistance and beta-cell function from fasting plasma glucose and insulin concentrations in man. Diabetologia 1985, 28, 412-419. [CrossRef] [PubMed]

29. Augustin, L.S.A.; Kendall, C.W.C.; Jenkins, D.J.A.; Willett, W.C.; Astrup, A.; Barclay, A.W.; Björck, I.; Brand-Miller, J.C.; Brighenti, F.; Buyken, A.E.; et al. Glycemic index, glycemic load and glycemic response: An International Scientific Consensus Summit from the International Carbohydrate Quality Consortium (ICQC). Nutr. Metab. Cardiovasc. Dis. 2015, 25, 795-815. [CrossRef] [PubMed]

30. Sievert, Y.A.; Schakel, S.F.; Buzzard, I.M. Maintenance of a nutrient database for clinical trials. Control. Clin. Trials 1989, 10, 416-425. [CrossRef]

31. Kriska, A.M.; Bennett, P.H. An epidemiological perspective of the relationship between physical activity and NIDDM: From activity assessment to intervention. Diabetes. Metab. Rev. 1992, 8, 355-372. [CrossRef]

32. Madeira, F.B.; Silva, A.A.; Veloso, H.F.; Goldani, M.Z.; Kac, G.; Cardoso, V.C.; Bettiol, H.; Barbieri, M.A. Normal weight obesity is associated with metabolic syndrome and insulin resistance in young adults from a middle-income country. PLoS ONE 2013, 8 , e60673. [CrossRef] [PubMed]

33. Bunout, D.; de la Maza, M.P.; Barrera, G.; Leiva, L.; Hirsch, S. Association between sarcopenia and mortality in healthy older people. Australas. J. Ageing 2011, 30, 89-92. [CrossRef] [PubMed]

34. Alicandro, G.; Bisogno, A.; Battezzati, A.; Bianchi, M.L.; Corti, F.; Colombo, C. Recurrent pulmonary exacerbations are associated with low fat free mass and low bone mineral density in young adults with cystic fibrosis. J. Cyst. Fibros. 2014, 13, 328-334. [CrossRef] [PubMed]

35. Vaisman, N.; Pencharz, P.B.; Corey, M.; Canny, G.J.; Hahn, E. Energy expenditure of patients with cystic fibrosis. J. Pediatr. 1987, 111, 496-500. [CrossRef]

36. Turck, D.; Braegger, C.P.; Colombo, C.; Declercq, D.; Morton, A.; Pancheva, R.; Robberecht, E.; Stern, M.; Strandvik, B.; Wolfe, S.; et al. ESPEN-ESPGHAN-ECFS guidelines on nutrition care for infants, children, and adults with cystic fibrosis. Clin. Nutr. 2016, 35, 557-577. [CrossRef]

37. Matel, J.L. Nutritional Management of Cystic Fibrosis. J. Parenter. Enter. Nutr. 2012, 36 (Suppl. 1), 60S-67S. [CrossRef]

38. Gaskin, K.J. Nutritional care in children with cystic fibrosis: Are our patients becoming better? Eur. J. Clin. Nutr. 2013, 67, 558-564. [CrossRef] [PubMed]

39. Prévotat, A.; Godin, J.; Bernard, H.; Perez, T.; Le Rouzic, O.; Wallaert, B. Improvement in body composition following a supervised exercise-training program of adult patients with cystic fibrosis. Respir. Med. Res. 2019, 75, 5-9. [CrossRef]

40. Papalexopoulou, N.; Dassios, T.G.; Lunt, A.; Bartlett, F.; Perrin, F.; Bossley, C.J.; Wyatt, H.A.; Greenough, A. Nutritional status and pulmonary outcome in children and young people with cystic fibrosis. Respir. Med. 2018, 142, 60-65. [CrossRef]

41. Fielding, J.; Brantley, L.; Seigler, N.; McKie, K.T.; Davison, G.W.; Harris, R.A. Oxygen uptake kinetics and exercise capacity in children with cystic fibrosis. Pediatr. Pulmonol. 2015, 50, 647-654. [CrossRef] 